\title{
Population Growths and Socio-Economic Development: An Analysis of Mettu Town of Ethiopia
}

\author{
https://doi.org/10.21272/sec.3(1).52-63.2019
}

\section{SN Singh}

Dr, Associate Professor of Economics and Law in the Department of Economics, Faculty of Business and Economics, Mettu University, Ethiopia

\begin{abstract}
This paper summarizes the arguments and counterarguments within the scientific discussion on the issues of population growth and socio-economic development in Ethiopia. The main purpose of the research is to analyze the relationships between population growth and socio-economic development in Ethiopia on broad scene and case study is supported to the Mettu town of Ethiopia. Systematization literary sources and approaches for solving the problem have been adopted for the data collection, methodology followed, analysis and presentation. The result indicates that there is a negative impact of population growth on socio-economic development in the town concern. The relevance of the decision of this scientific problem is that how population growth affects socio-economic development in the country. Investigation of the research topic on population growth and socio-economic development in Ethiopia have been carried out in the following logical sequence: the causes of population growth including both natural and migration particularly from rural to urban areas, how the population growth affects various socio-economic indicators like income, wealth and material possession etc. The methodological tools of the research methods were descriptive statistical analysis including quantitative and qualitative techniques. The research is conducted recently particularly in the year 2018 . The object of research is the chosen at country level, followed by regions, and town, because namely they Ethiopia, Oromia and Mettu respectively. The paper presents the results of an empirical analysis of population growth and its impact on the family size, dependence ratio and unemployment etc, which showed that high population directly affect the land fragmentation, shortage of food per capita at some household level, shortage of social and economic services and other co-related associated problems. The research empirically confirms and theoretically proves that there is an inverse relationship of population growth on socio-economic development in Ethiopia. The results of the research can be useful for the policy makers, academicians and researchers etc.
\end{abstract}

Keywords: population growth, socio-economic development, marriage polygamy and family planning.

JEL Classification: J11, O12, D12.

Cite as: Singh, SN (2019). Population Growths and Socio-Economic Development: An Analysis of Mettu Town of Ethiopia. SocioEconomic Challenges, 1(3), 52-63. https://doi.org/10.21272/sec.3(1).52-63.2019.

(C) The Author, 2019. This article is published with open access at Sumy State University.

\section{Introduction}

\subsection{Background of the Study}

The world is now highly populated as it had never before. This increment of population occurred continually starting for the ancient time to now. When peoples first started cultivation of food through agriculture some 1200 year ago, the stated world population was no more than 5 million. At the beginning of Christian era 200 years ago, the world population had grown to nearly 250 million. From A.D it the beginning of industrial revolution around 1750, it tripled to 728 million. During the next 200 years (1751-1950) an additional 1.7million people were added to the earth's numbers. However, in just for decades here after (1950-1995) the world population was doubled more than again bringing in the total figure to over 5.5 million. This trend continued and the number reached to 6.3 million by the year 200 (Todaro et. Al., 2009).

African countries are confronted extremely difficult problem of eliminating the poverty and struggles for their economic growth. The population growth that is around $75 \%$ of the world population lives in the countries of the world population of approximately 5.5 million 2004, more than 3/4 live in the third world countries and less than $1 / 4$ in the more developed nations (Todaro et. Al., 2009). Ethiopia is a $3^{\text {rd }}$ most populated country in African continent having a population size of 88.5 million in 2007 and a growth rate is about 2.7 percent of rural population which constitutes about 85 percent of the total population and that is mainly depending on 
farming and their income level below 1 \$ USA per day (Ethiopian National Census 2007). The Oromia region is having about 43 million population and the socio-economic activities of the population is based on agriculture. The income level of the people is per day 1\$USA. The 2007 National Census of Ethiopia reported that a total population of Mettu was 28726 and but now estimated around 41231 that comprise 21027 men and 20204 women (Administrative office Mettu town; 2008).

\subsection{Statement of the Problem}

The link between population growth and socio- economic development is not as simple as cause and effect relationship. There is bi-directional relationship between the two, one affecting the other socio- economic growth affects population growth and population growth has impact on the socio- economy development.

There has been on consensus whether population growth positive or negative impact on the performance of socio- economic is still unsolved. This term paper was regarding to the problems and explains the impact of population growth on socio- economic development in different aspects. The population growth is the main source of labor supply in socio- economy. With our all population, the working age (15-64 year age) the population increase resulting in an increase labor force. The size of working age -population (the labor force) has significant contributed for development of socio- economy. The economy observes and makes use of It (Zinash zeleke. ET, al., 2004).

Rapid population growth in Ethiopia has aggravated for existing gap of unmet need of social service and the quality of health and education services in the country and have been continued to be deteriorated by rapid population growth (Befekadu et al., 1999). Both of them are suggesting the different ideas about impact of rapid population growth on socio-economic development that leads to increase the rate of labor force in economy and Deteriorating further the quality of social services. This research study was motivated to identify macroeconomics variable like income, education, and health status etc. and the impact of population growth on socio economic development of Mettu town.

\subsection{Objective of the study}

\subsubsection{General objective of the study}

The present study is intended to identify the impact of rapid population growth on the socio- economic development particularly on education and health in Mettu town of Oromia region of Ethiopia.

\subsubsection{The specific objective of the study are as:}

$>$ To access the factors responsible for rapid population growth in Mettu Town.

$>$ To examine the consequences of rapid population growth on socio economic development.

$>$ To suggest policy recommendation to overcome with the acute problem of population growth.

\subsection{Research questions}

The following will be raised in the motivation for conducting the study.

$>$ What is the effect of rapid population on socio- economic development of Mettu town?

$>$ What are the determinants of rapid population growth in Mettu town?

\subsection{Significance of the study}

This study would be expected to provide base line information concerning to the population growth and socioeconomic development in case of Mettu town.

The paper of research hopes to identifying the various problem related to population growth and socio-economic development.

\section{Review of literature}

\subsection{Definition and theoretical}

In terms human biology encyclopedia Brita mica defines population as whole numbers of people occupying an area (such as country or world) and continually being modified increases birth rate and immigrations (BRI) or loses (depth migrations) encyclopedia Britannica values 25). On the other hand population growth as by 
international encyclopedia of social science is the rise in the number of person living at a given moment of time. However, the growth is necessarily positive or monotonic; it is the sum of natural increase only where rot migration is nil or legible. Historically the definition of economic development has been continued to per capital real income until recently the meaning has gained wider scope. It can be defined as nothing less than upward movement of the entire social system or I may be interpreted as attainment of the idea, such as arise in productivity, social and economic equalization of modern knowledge improved attitudes, rationally coordinated sustain of policy measure of under development (Meir, 1995).

\subsubsection{Theoretical view}

The world's populated today's it have never do for although rate of population growth have fallen and we'll continue to fall, we currently and about million people every 4 days to the world population net of death. Robert Malthus, the prominent demographer believed that population growth and development have great link.

He compared the since of population economic growth of the time and that of Jaluis Caesar's "Europe is match more populous now than it was former time it's that the industry of them in habitant has the countries produce quantity of human substance"(Malthus, et,al.,1978).

\subsubsection{The ancient Greeks view}

The ancient Greek writers were concerned with formulation of policies and rules for population. In their writing, there is no organized theory about population. Plate and Aristotle discussed quest of optimum population with respect to Greek city state their writing on the ideal condition for full development of human potential.

\subsubsection{Muslims view}

Muslims view seems a little bit population is the Hebrew ad early Christiana, as the restriction is as Hebrew and early christens as restriction in the formers. The case of worried persons is different from that of outsiders. If one of them accuses of unchastely, the acquisition parity reflect the as well.

\subsubsection{Mercantilists view}

Merchant writers called mercantilists, dominated the period 1500-1776 they were dominant particularly in Britain and France. Their philosophy was based on nation and national superiority, possession of precious metal like, gold, silver and favorable balance that means excess export over important and generally to rich at the expense of other nation. The desire for a large portion intensified in the $17^{\text {th }}$ Europe under the influence of mercantilism. The central aim of this school was to increase the power and health of nation. It was through that population growth would contribute greatly to this goal. Especially skilled worker were encouraged. For mercantilists wealth is measured in term is of accumulative gold and silver. Hence, high production is essential to build the military power of government in order to colonize counties that are rich in gold and silver mines. They also argue that population enable to have huge supply of labor that enable the low wage rate. Thus reduction in domestic production at the international market (IM) (Spieger et al., 1989). Commercial were the German country part of mercantilists their writing wee spread over 300 year in Australian and other German state. They were primarily concerned with feeling the treasury of the prince. They were to ensure that the fertility of the source of revenue never declined (Bhatia, 1988).

Towards the end of mercantilist and before the beginning of physiocratic school of thought (during the transaction period) Sir William pretty come up an optimistic idea of population he that population growth is principal factors in determining economic growth. Hennery William Spiegel put putt's views "to William petty population growth rather than investment is the principal force of dynamism that promotes economic progress" (Spegel, et al., 1989).

\subsubsection{Physiocratic view}

In $18^{\text {th }}$ century physiology emphasized agriculture and the need to growth sufficient food for large population. However, during that period there was considerable optimism about population growth I west Europe, William god will Britain asserted late in $18^{\text {th }}$ that excessive population would never be a problem for a nation. There is principle in human society by which population is perpetually kept to the means of substance. Thus, among that population has so increased as to render necessary the cultivation of earth. He further explain my raids century of still increase population path away the earth be found sufficient for the subsistence of its in habitant (Malthus et al., 1978). 


\subsubsection{The theory of demographic transition}

Country to most other theories of population the theories of population transition derived from actual historical experience. It designed to explore their stage of modern population theories in which anticipate the future demographic trend in countries present, in the early phase of transaction. Before their economic modernization today has developed countries where characterized by a stable or very slow population growth population of high birth rate. This was stage one a demographic transition. This stage has completed its operation in developing countries now (Todaro et al., 1994).

Stage two, known for its high rate of population growth .it associated better public health method, health directs, high income, and improvement. All these make reduction in mortality that gradually raised life expectancy. In the stage there, the in fertility, converge $\mathrm{d}$ with the decline in death rate leaving little or no population growth.

\subsection{Empirical literature of ethiopia}

Countries have seriously affected the development of the economic growth rate GDP perception GDP and have declined with growth of the population. For instant the GDP growth of rate in 1978 was four times higher that of the 1990 while per capital GDP declined to almost zero in 1990, from 2.1 in 1978 (Berhanu et al., 1999-2000).

Experience over the last couple of decades in Ethiopia has shown that human numbers increased the population carrying of environment decrease. High population growth rate included increasing for recourse and rate at which the greater productivity environment harm full economically country productive methods of exploiting land associated source are reported in order to meet immediate needs. Because of this, climate condition become erratic and soil quality declining at alarming rate (Befekadu Degefa et al., 2006).

Empirical evidences on Ethiopia agriculture and population growth shows at that there is wide gap between population growth and corresponding growth in food production declining per capital production low erratic conception and increase food in security and resource exploitation are likely consequence of population pressure in Ethiopia. In Africa context in population growth in sub-Saharan African for example the growth of capital food production is $2 \%$ which the population growth at 3\% per annum (Abdi et al., 1995).

Crop production area have lost their productivity here are several sides to problem but more importantly loss of productivity is a function of increasing mass land ratio occupied rapid population growth. Hence, per capital food production has continuously (Berhanu et al., 1999-2000).

Rapid population growth in Ethiopia aggravated the existing gap of unmeant need for social service the quality of health and education service the quality of health and education service in the country have been and continued being deteriorated by growth population. The demand for food is directly associated with as sized of population. A rapid growth of population requires as fast increase agricultural production to insure enough food, supply food upcoming generations. The situation of supply has been worsening in Ethiopia recently.

\section{Methodology of the study}

\subsection{Study area}

Mettu town is one of the Oromia regional state's Zone which is located on the south- west direction from Addis Ababa with a distance of about 600 kilometers. This town has latitude and longitude of 8.18'N, $35.35^{\prime} \mathrm{E} / 8.30 \mathrm{~N} 35.583 \mathrm{E}$ altitude of $1605 \mathrm{~m}$ above sea level. This town was the capital of former Illu Aba Bor province from 1978 until the adoption of the new constitution in 1995. According to the town census reported that the total population of Mettu Town is 41231 comprising 20204 women and 21027 men. As per annual the rainfall $1500 \mathrm{~mm}-2000 \mathrm{~mm}$, temperature 18 'c-22'c and the elevation of Mettu town is found in weing Dega (semi-humid climate zone). This type of climate is amicable for both human habitation and economic activities.

\subsection{Data source}

The data source that would be ready to use were both primary data and secondary data sources. The primary data source would be too obtained from questioners and direct observation of the family numbers with their social-economic level. The secondary data source would be too obtained from report formats, published 
profiles from different perspective a case of Mettu town. This would do to ensure anonymity and encourage more honest and reliable answers.

\subsection{Data collection techniques}

A well defined questionnaire was used to collect information from the respective respondent. The collected data was analyzed and interpreted by using tools techniques like percentage, graphs etc.

\subsection{Sampling techniques and sampling size}

Because of time and budget constraint the researcher was selected 100 respondents in Mettu town and Simple random listing of probability techniques for the fact that accessed population equal chance to be a respondent in Mettu town.

The following formula is used to determine the size of sample

$\mathrm{n}=\mathrm{N} / \mathrm{N}(\mathrm{e}) 2$

$\mathrm{n}=$ sampling size

$\mathrm{N}=$ proportional to population

$\mathrm{e}=$ perception of error

$\mathrm{e}=0.1$

$\mathrm{N}=41231$

$\mathrm{n}=41231 / 41231(0.1) 2=100$

Therefore, the sample size was selected as 100 respondents among total population of 41231 . The central limit theorem is applicable as normalize the distribution. Out of 100 respondent 43 women and 57 men respondent were interrogated for specified questions as set in questionnaires.

\subsection{Methods of data presentation and analysis}

The analysis of data involves descriptive types of data gathered from respective source was organized and classified according to their similarities and the researcher was used quantitative data analysis and presentation and qualitative tools represented by table, graph and percentage. The analysis important document was made in a way that can be easily understands.

\section{Data Analysis and Interpretation}

Data analysis and interpretation was used both primary and secondary data and from the total of population 41231 the 100 respondents were selected by using simple random sample of probability sample techniques. And the data was analyzed by using table, chart, and percentage the population development is highly interrelated one affecting performance of status, family size, occupational status, health status and income level population is analyzed that is crucial for policy formulation and economic analysis and development.

\subsection{Backgrounds of respondents}

Table 1. Sex interpretation of respondent

\begin{tabular}{|c|c|c|}
\hline Sex & Respondent & Percentage $\%$ \\
\hline Male & 57 & 57 \\
\hline Female & 43 & 43 \\
\hline Total & 100 & $100 \%$ \\
\hline
\end{tabular}

Source: household survey, 2008 E.C.

The above table 1 show that the respondent by sex with the total samples of household, the number of the male is $57(57 \%)$ and $43(43 \%)$ are female. 


\subsection{Age Distribution of Selected Household}

Table 2. Age distribution of the selected households

\begin{tabular}{|c|c|c|c|c|}
\hline Age group & Male & Female & Total & Percentage $\%$ \\
\hline $10-20$ & 8 & 5 & 13 & 13 \\
\hline $21-30$ & 10 & 2 & 12 & 12 \\
\hline $31-40$ & 10 & 6 & 16 & 16 \\
\hline $41-50$ & 10 & 8 & 18 & 18 \\
\hline $51-60$ & 10 & 10 & 24 & 24 \\
\hline $61-65$ & 9 & 12 & 21 & 21 \\
\hline
\end{tabular}

Source: household survey, 2008 E.C.

Table 2 shows that the selected respondent household out of size $13 \%$ are age group 10-20,12\% age group are $21-30,16 \%$ age group are $31-40,18 \%$ age group are $41-50$ and $24 \%$ respondents age group are $51-60$ and $21 \%$ of respondents are 61-65. The majority of respondent household economically active and biologically productive age group. But the existing problems of the selected as they told the shortage of farmland, lack of alternative source of live hood and shortage of income in house hold level.

\subsection{Respondent of education status}

Table 3. Respondent level of education status

\begin{tabular}{|c|c|c|c|c|c|}
\hline No & Educational status & Male & Female & Total & Percentage $\%$ \\
\hline 1 & Illiterate & 20 & 10 & 30 & 30 \\
\hline 2 & $1-4$ & 10 & 15 & 25 & 25 \\
\hline 3 & $5-8$ & 10 & 5 & 15 & 15 \\
\hline 4 & $9-12$ & 5 & 5 & 1 & 10 \\
\hline 5 & Diploma & 6 & 4 & 10 & 10 \\
\hline 6 & Degree & 67 & 43 & 100 & 10 \\
\hline & Total & $57 \%$ & $43 \%$ & & $100 \%$ \\
\hline
\end{tabular}

Source: household survey, 2008 E.C.

As indication of table 4.3 out of total respondent $30 \%$ are illiterate $40 \%$ completes primary school (1-8), $10 \%$ are complete secondary and preparatory school (9-12) and 10\% have a diploma $10 \%$ have degree. Education is an additional factor that is also through to influence the socio-economic status of households. Education equips indicial with the necessary knowledge of how to make living educational attainment by households lead to awareness and benefits from the possible advantage of additional business making knowledge, actively participate in family planning service with would capitals and it was this assumed to play a role in the determining a socio-economic improvement. But the above data indicate the existence of high illiterate and lack family planning technique that cause for rapid population growth.

\subsection{Respondent household's marital status}

Table 4. Respondent's household's marital status

\begin{tabular}{|c|c|c|c|c|c|}
\hline No & Marital status & Male & Female & Total & Percentage\% \\
\hline 1 & Single & 20 & 8 & 28 & 28 \\
\hline 2 & Married & 25 & 19 & 44 & 44 \\
\hline 3 & Polygamy & 6 & & 6 & 6 \\
\hline 4 & Divorced & 6 & 6 & 12 & 12 \\
\hline 5 & Windowed & & 10 & 10 & 10 \\
\hline & Total & 57 & 43 & 100 & 100 \\
\hline & Percentage & $57 \%$ & $43 \%$ & & $100 \%$ \\
\hline
\end{tabular}

Source: own survey, 2008 E.C. 
The above table 4 shows marital status of respondent out of total sample household $44 \%$ married, $6 \%$ polygamy, and $28 \%$ single, $12 \%$ divorced and $10 \%$ are widowed. This indicates marital status the rapid increment of population in study area. The consequence of polygamy, early marriage and lack of family planning service contribute to for the increasing of family size as household. It brought high rate population growth beyond the capacity of the land size and serious effects on the quality of the people in terms of access to education, health and leaving facilities and economic implication.

\subsection{Family size of the respondents}

Table 5. The family size of the respondents

\begin{tabular}{|c|c|c|}
\hline Family size & \multicolumn{2}{|c|}{ Number of the respondent } \\
\hline Interval & Frequency & Percentage \\
\hline$<5$ & 25 & 25 \\
\hline $5-9$ & 35 & 35 \\
\hline$>10$ & 40 & 40 \\
\hline Total & 100 & 100 \\
\hline
\end{tabular}

Source own survey 2008 E.C.

As table 5 indicates that, out of 80 total samples $25(25 \%)$ respondents have less than four children and $35(35 \%)$ respondents have between 4-7 children but 40(40\%) respondents have greater than ten children. So the majority of the respondent's family size is greater ten children. This shows that, they have large family. The reason they have large family, they lack of farm land, productivity in quality and quantity, housing problem, health problem and even they have no opportunity to attend education then the population can simply cause by food insecurity.

\subsection{Respondent household by religion}

Table 6. Respondent household by religion

\begin{tabular}{|c|c|c|c|c|c|}
\hline No. & Religion Status & Male & Female & Total & Percentage $\%$ \\
\hline 1 & Orthodox & 30 & 20 & 50 & 50 \\
\hline 2 & Protestant & 20 & 18 & 38 & 38 \\
\hline 3 & Wake fate & 6 & 3 & 9 & 9 \\
\hline 4 & Traditional & 1 & 2 & 3 & 100 \\
\hline 5 & Total & 57 & 43 & 100 & $100 \%$ \\
\hline 6 & Percent & $57 \%$ & $43 \%$ & & \\
\hline
\end{tabular}

Source: primary household survey, 2008 E.C.

The above table 6 illustrate that the religious has its own factor that contributes the rapid growth of population in study area. Out of total respondent the highest percent share is orthodoxy (50\%) the second protestant (38\%) and wake fate (9\%) and traditional Oromo religious follower was (3\%).different religion followers people have different attitude about family planning service and its importance depend upon their religious doctrine; they believe that using family planning as breaking divine law, due to this they reject scientific way of family planning to some extent this is the major cause for rapid population growth in the town. Furthermore, the religious has influence attitude of society to ward job activities many religious people devote their time to celebrate religion activities. As result, a person lends their life under poverty vicious circle and these discourage the productivity of economically active people of this society and community of the area.

\subsection{Respondent household land housing in hectare}

Table 7. Respondent household land housing in hectare

\begin{tabular}{|c|c|c|c|c|c|}
\hline No & Landsite in hectare & Male & Female & Total & Percentage $\%$ \\
\hline 1 & $0.025 \mathrm{ha}$ & 10 & 11 & 21 & 21 \\
\hline 2 & $0.25 \mathrm{ha}$ & 12 & 8 & 20 & 20 \\
\hline 3 & $0.5 \mathrm{ha}$ & 14 & 7 & 21 & 21 \\
\hline 4 & $0.75 \mathrm{ha}$ & 10 & 7 & 17 & 17 \\
\hline 5 & $1 \mathrm{ha}$ & 11 & 43 & 100 & 21 \\
\hline & Total & 57 & $43 \%$ & 100 & $100 \%$ \\
\hline
\end{tabular}

Source: own survey 2008 E.C. 
The above table 7 indicates from the respondents $21(21 \%)$ the land size are $0.025 \mathrm{ha}, 20(20 \%)$ land $0.25 \mathrm{ha}$, $21(21 \%)$ are 0.75 ha, $18(18 \%)$ and only $21(21 \%)$ are greater than 1 ha. The data implies that the majority of the households very small land size in the study area because of rapid population growth land fragmented. There is inverse relationship with population size and farm land size. This implies agricultural output and productivity of agriculture production are constrained in case of land fragmentation and traditional faming method.

\subsection{Respondent household sources of live hoods}

Table 8. Respondent household source of livelihoods

\begin{tabular}{|c|c|c|c|c|c|}
\hline No & Source of income & Male & Female & Total & Percentage \% \\
\hline 1 & Agriculture & 20 & 5 & 25 & 25 \\
\hline 2 & Trade & 22 & 23 & 45 & 45 \\
\hline 3 & Government employee & 10 & 10 & 20 & 20 \\
\hline 4 & Handicraft & 5 & 5 & 10 & 10 \\
\hline & Total & 57 & 43 & 100 & 100 \\
\hline & Percentage & 57 & 43 & & $100 \%$ \\
\hline
\end{tabular}

Source: ousehold survey, 2008 E.C.

\section{Chart graph}

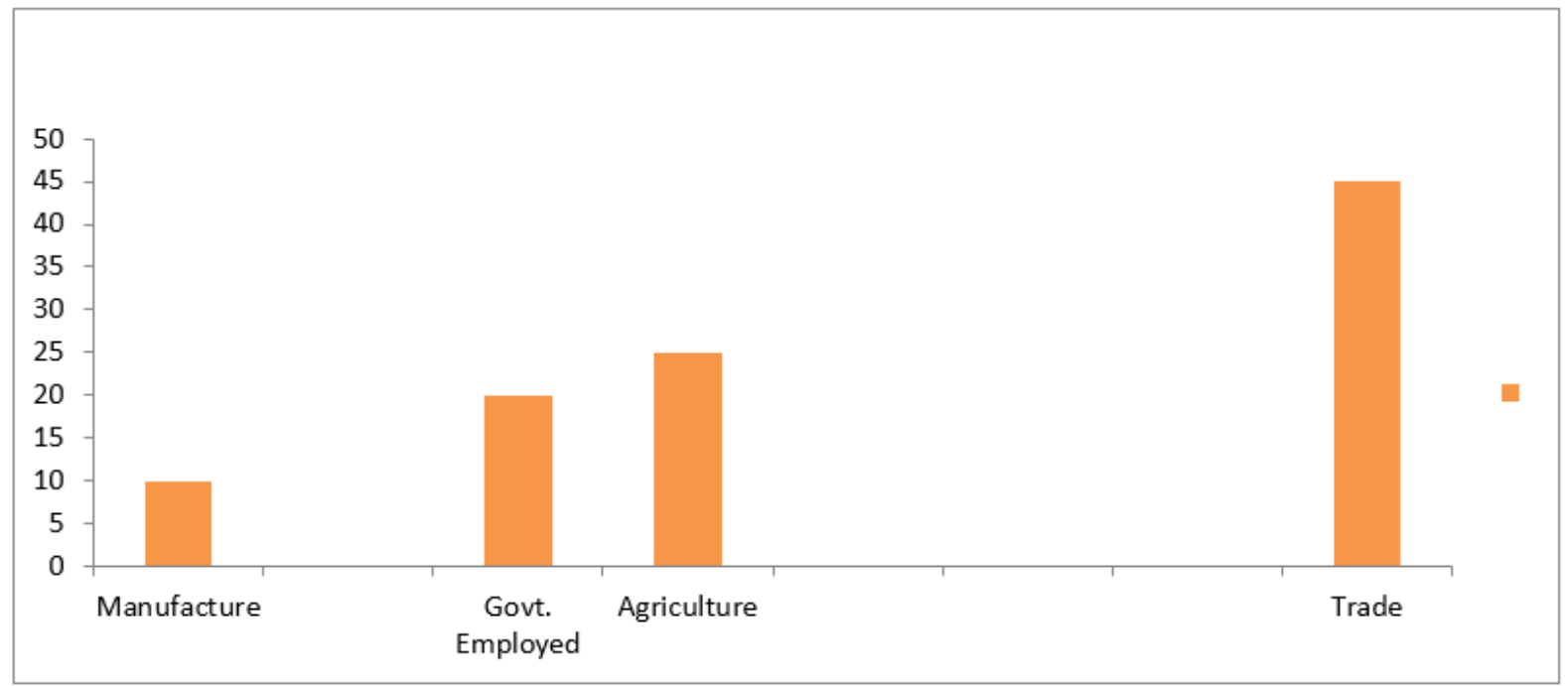

Figure 1. Occupational status of respondent

Source: primary household survey, 2008.

According to the study household lives hood 25\% agriculture (primary economic activity, $45 \%$ trade and 20\% are government employers). It has negative relationship between agricultural land sizes in the town. This implies high land fragmentation and it is impossible to harvest enough yield of crop for annual.

\subsection{Respondent monthly household incomes}

Table 9. Respondent monthly household income

\begin{tabular}{|c|c|c|c|c|c|}
\hline No & Income categories & Male & Female & Total & Percentage $\%$ \\
\hline 1 & $500-1000$ & 17 & 10 & 27 & 27 \\
\hline 2 & $1000-1500$ & 11 & 7 & 18 & 18 \\
\hline 3 & $1500-2000$ & 9 & 10 & 19 & 19 \\
\hline 4 & $2000-2500$ & 8 & 6 & 14 & 14 \\
\hline 5 & $>2500$ & 12 & 10 & 22 & 22 \\
\hline & Total & 57 & 43 & 100 & 100 \\
\hline & Percentage & $57 \%$ & $43 \%$ & & $100 \%$ \\
\hline
\end{tabular}

Source: primary household survey, 2008 E.C. 
The above table 9 show that the income of respondent under income categories.

The data indicate that the majority of the populations earn income between (500-1000)17\%, (1000-1500)18\%, (1500\%-2000\% 19\% and (2000-2500)14\%. This implies that the majority of population concentrated in lows income categories, and the range between high income and low income is high and there is significant disparity exist between household in relative level of income. Because the majority of population depends on agricultural activity and land is not abundant in the town because of rapid population growth and land fragmentation. And also traditional way of economic activity land unable to harvest enough yield of crop annual.

Children of large families tend to perpetuate the vicious circle poverty by having more children themselves. These also support the above analysis.

\subsection{Population growth rate in Mettu town}

Table 10. Population growth trend and annual average growth in the town.

\begin{tabular}{|c|c|c|c|}
\hline No & Year & Population & Percentage \\
\hline 1 & 2012 & 34713 & 2.58 \\
\hline 2 & 2013 & 35812 & 2.42 \\
\hline 3 & 2014 & 37259 & 2.78 \\
\hline 4 & 2015 & 39063 & 2.83 \\
\hline 5 & 2016 & 41231 & \\
\hline & Total & & \\
\hline
\end{tabular}

Source: administrative office of Mettu town 2008 E.C.

Population rate $=(\text { value present }- \text { value past/ value past } / 2)^{*} 100$

The above tables 4.10 indicate that averagely annual grows rate of population in Mettu town. In 2012 it grows at 1.58 but today it grows at 2.83 this implies that increment of population occurred time after time. Hence it's not only rate of growth but total size of population is changed. This rapid population growth of Mettu town, currently estimated as a total population 41231 which expected to grow the rapid increment out of the carrying capacity of land size and other impact on socio-economic activities and but the next year estimation of population will become around 43561. (Administrative office of Mettu town 2008 E.C.).

\subsection{Educational status}

Educational directs impious producing rate of return and earning of people in addition to this education had wide range of in direct effects with investigates positive changes people attitude toward work and society. The importance of qualifying of people as-productive agent has recently been regarded as the central objective of developing countries people's ability and skill have to be improved and their motivation and values modified in order to make them more suitable for development effort. Increasing education standards of the work force enable the greater output to be obtained number of workers.

Table 11. The school attendance and sex in Mettu town.

\begin{tabular}{|c|c|c|c|c|c|}
\hline No. & Educational status & Male & female & Total & Percentage $\%$ \\
\hline 1 & Current never attending the school & 23 & 32 & 55 & $55 \%$ \\
\hline 2 & Current attending the school & 16 & 14 & 30 & $30 \%$ \\
\hline 3 & Past attending the school & 10 & 5 & 15 & $15 \%$ \\
\hline
\end{tabular}

Source; own survey 2008 E.C.

The above table 11 data it indicate the school attendance and sex that out $55 \%$ of people, $32 \%$ are female and $23 \%$ male are never attending the school, $39 \%$ of people $16 \%$ are male and $14 \%$ of female are current attending school and about $15 \%, 10 \%$ of male and $5 \%$ female are attending school in the past. The higher percentages of never attending school are the major course of rapid population growth because women who do not have formal education have more children than women with formal education lack family planning techniques. The number of children desired decrease as educational level increase.

These un attend people are due to different problem that are limited access of school, lack of awareness of the necessity of school education, economic problems, cultural influence and others are occupied by other activity. 
Country to this population leads to increase in the school population on the family level, the increase in population leads parent to allocate large portion of their current income to ward children for education and consumption. Since the income of parents is not support all of his children, and they usually unable to spend income on those child as they did, even if their income has been rising because of large number of children are unable able to support their children. This is tends to return economic growth of town, low living standards and low saving, which is essentials for investment and vicious circle poverty government in developing countries according education high priority because of population pressure and partly lack of trained man power is one of critical obstacle in way of faster economic growth(meier,1989;450).

\subsection{The health status}

Health service forms the basic social need of the society. Health is a factor development endeavor of the products of nation and wellbeing of health status for utilization. Improved health also contributes directly to economic growth while good health drives satisfactory. The following table shows health status of on the town.

Table 12. Health status

\begin{tabular}{|c|c|c|c|}
\hline No & Health status & Male & Female \\
\hline 1 & Good & $5(5 \%)$ & $5(8 \%)$ \\
\hline 2 & Satisfactory & $14(14 \%)$ & $5(5 \%)$ \\
\hline 3 & Poor & $38(38 \%)$ & $30(30 \%)$ \\
\hline
\end{tabular}

Source: Primary household survey, 2008 E.C.

The above table 12 indicates that $13 \%$ are good service, $19 \%$ are satisfactory service and $68 \%$ are poor service. Thus mass of the population face challenge to get adequate health service. Malnutrition and disease concern that of high population growth and poor are unable to receive access to sufficient health are moreover, the number of physicians in the town is not compatible with the number of population of town in general wide spread of poverty, malnutrition, how education level, in adequate access to clean water and sanitation facilities have contributed is not compatible with the number of the population of Mettu town.

In general wide spread of poverty, malnutrition low educational level, in adequate access to clean water and sanitation facilities have contributed to high degree of illness health in the town area. This situation is caused by rapid population growth.

\section{Conclusion and Recommendations}

\subsection{Conclusions}

The main objective of this study is to investigate the socio-economic impact of rapid population growth in Mettu town. According to little available information, this paper draws more attention on the socio-economic impact of rapid population.

The review of demographic trend in mettu town that population has increase rapidly, this incremental of new born to the population every year is due to different factor. Those are early marriage polygamy, those who have more than one wife, lack of education, religious impact, because of they depend up on their religious doctrine.

They believe that using family planning as breaking that is the main course for rapid population growth. And the other social attitude, they believe in or seen as having more children is economic investment of goods, in that there is an expected return inform of both labor and procession of financial support for parent in old age. Also sex preference has its own role in population growth.

The overall impact of population growth are observed first in excessive land fragmentation, high dependence ratio, and high rate of unemployment, shortage of food at household level and low social service. As a result, the livelihood of many household is gradually deteriorating and incomparable with the family size. This has made most families to face several problems such as shortage of income level medical care, education, and other basic requirements are constraint the study area people. 
SocioEconomic Challenges, Volume 3, Issue 1, 2019

ISSN (print) - 2520-6621, ISSN (online) - 2520-6214

\section{Recommendation}

The research study proposes the following policy recommendations based on the findings.

$\checkmark$ Special programs are required for raising awareness about family planning of the community.

$\checkmark$ It is better elementary education is essential for all.

$\checkmark$ It is better to increase the awareness about infectious diseases like HIV/AIDS etc. must be imparting at grassroots level.

$\checkmark$ Encouraging and promoting the late marriage by the government that is important to reduce the affective child bearing of woman.

$\checkmark$ Its better when government increase the number of job opportunity available through job creating in order to reduce unemployment problem.

$\checkmark$ Society are better to understand the problem of fertility or problem that cause by fertility and attempt to reduce high fertility by using family planning.

\section{References}

1. Abdi Mano (1994). The nexus among environmental population and agricultural development in Ethiopia, 3rd edition.

2. Adam, A. G.(2014). Informal settlements in the peri-urban areas of Bahir Dar, Ethiopia: an institutional analysis. Habitat International, 43, 90-97.

3. Administrative office of Mettu town (2008). Oromia region of Ethiopia.

4. Aman, M. (2014).Postharvest loss estimation of cut rose (Rosa hybrida) flower farms: economic analysis in East Shoa Zone, Ethiopia. International Journal of Sustainable Economy, 6(1), 82-95.

5. Ashford, Lori S. (2009). Africa's Youthful Population: Risk or Opportunity? USAID, Population Reference Bureau. Website: www.prb.org.

6. Berhanu Nega and Befekadu Degefe (1999). Annual report on Ethiopia; the Ethiopia economics association ends. Addis Ababa.

7. Bhatia, H.L. (1989). History of Economic Thought, 3rd ed. Vikas Publishing House Pvt. Ltd.

8. Birdsall, N. (1989). Economic analyses of rapid population growth. The World Bank Research Observer, $4(1), 23-50$.

9. Coale, A. J. and Hoover, E. M. (1958). Population Growth and Economic Development in Low Income Populations. Princeton: Princeton University Press.

1. Galor, O. and Weil, D. N. (2000). Population, Technology,

10. and Growth: From Malthusian Stagnation to the Demographic Transition and Beyond. The American Economic Review, 90(4), 806-828.

11. Hajela, T.N. (1967) History of Economic Thought.

12. Harrison, P. (1992). The Third Revolution: Population, Environment and a Sustainable World. Penguin Books Ltd, England.

13. Hogedorn, J.C. (1994). Economic Development. NewYork, Harper Collins Publisher.

14. Kremer, M. (1993). Population growth and technological change: one million BC to 1990. The Quarterly Journal of Economics, 108(3), 681-716

15. Latimer, A., Kulkarni, K. (2008). Population Explosion and Economic Development: Comparative Analysis of Brazil and Mexico. Knowledge Hub, the Journal of Rajiv Academy for Technology and Management (RATM), 4(2), 57-70.

16. Malthusian, T.R. (1798). An Essay on the principle of population. Oxford University Press. New York.

17. Mankiw, N., Romer, D., Weil, D. (1992). A Contribution to the Empirics of Economic Growth. QJE, 107(2), 407-437.

18. Merrick, T.W. (2002). Population and Poverty: New Views on an Old Controversy. Int. Fam. Plann. Perspect., 28(1), 41- 46.

19. Meire (1989). Leading Issue In Economic Development. NewYork; Oxford University Press.

20. Mutunga, C. and Hardee, K. (2009). Population and Reproductive Health in National Adaptation Programmes of Action (NAPAs) for Climate Change, In Population and climate change, edited by José Miguel Guzmán, M.J., Martine, G., McGranahan, G., Schensul, D. and Tacoli, C.

21. Nafziger, E. (2006). Economic Development, Fourth Edition. Cambridge University Press, New York. 
22. Ogawa, Naohiro and Rikiya Matsukura (2005). Ageing in Japan: The Health and Wealth of Older Persons. In: United Nations Expert Group Meeting On Social and Economic Implications of Changing Population Age Structures Mexico City, 31 August - 2 September 2005.

23. Ray, H. (1998). World Population Trends. New York, Oxford University Press.

24. Szotak, R. (2009). The Causes of Economic Growth. Interdisciplinary Perspectives. Berlin: Springer.

25. Tietenberg, Thomas H. (1992). Environmental And Natural Resource Economics.

26. Todaro (1994). Development Economics.

27. UN (2011a). World Population Prospects: The 2010 Revision, CD-ROM Edition, New York: Population Division of the Department of Economic and Social Affairs.

28. Yao, W., Kinugasa, T. and Hamori, S. (2013). An empirical analysis of the relationship between economic development and population growth in China. Applied Economics, 45(33), 4651-4661.

29. Yousif, H. (2009). How Demography Matters for Measuring Development Progress in Africa? Afr. Stat. J., 8, 12-27.

30. Zinash Zeleke (2004). Annual Report Of Ethiopia.

\section{Acronims}

GDP $=$ Growth Domestic Productive

BRI = Birth Rate and Immigration

IM = International Market

$\mathbf{A D}=$ After Death

E.C. = Ethiopian Calendar 